\title{
Uma tarefa Interdisciplinar sobre Sustentabilidade: desenvolvimento de uma WebQuest para promoção da Aprendizagem Significativa
}

\author{
Pablo Roberto F. de Oliveira ${ }^{1}$, Jucelio S. dos Santos ${ }^{2}$, Rodrigo A. Costa ${ }^{1}$, \\ Rosângela de A. Medeiros ${ }^{1}$ \\ ${ }^{1}$ Universidade Estadual da Paraíba (UEPB) \\ ${ }^{2}$ Universidade Federal de Campina Grande (UFCG) \\ pablorobertofernando@gmail.com, juceliodcopin.ufcg.edu.br \\ rodrigo@ccea.uepb.edu.br, professorarosangelauepbegmail.com
}

\begin{abstract}
The purpose of this paper is to analyze the use of a WebQuest in an activity developed in the classroom, through the production of a WebFind made by the students. The article presents suggestion and application of a task in which the student is instigated to relate some disciplines and associate diverse information with their knowledge. As a result, WebQuest has proven to be an effective tool for working with the digital generations, for how to disseminate and discuss the subject, making students enjoy doing research and producing material in a space so familiar and explored by them, as is the Internet.
\end{abstract}

Resumo. O objetivo deste artigo é analisar a utilização de uma WebQuest em uma atividade desenvolvida em sala de aula, através também da produção de um WebFind feita pelos alunos. O artigo apresenta sugestão e aplicação de uma tarefa em que o aluno é instigado a relacionar algumas disciplinas e associar informações diversas com seus conhecimentos. Como resultados, a WebQuest demonstrou ser um instrumento eficaz para trabalhar com as gerações digitais, pela forma de divulgar e discutir o assunto, fazendo com que os alunos sintam prazer em estar realizando uma pesquisa e produzindo um material em um espaço tão familiar e explorado por eles, como é a Internet.

\section{Introdução}

Um dos grandes desafios das escolas tem sido relacionar interdisciplinaridade e aprendizagem significativa em seus currículos. Ao mesmo tempo em que a gestão escolar tenta lidar com a inserção das novas tecnologias como ferramentas de apoio ao processo de ensino e aprendizagem, ora seja por meio de projetos instituicionais, ora seja por meio dos alunos que usufruem da acessibilidade às novas tecnologias em suas casas, lan houses, entre outros.

Dentro do âmbito educacional a interdisciplinaridade é caracterizada, basicamente, pela inter-relação de disciplinas. E, a aprendizagem significativa depende principalmente da disposição do aluno em associar o novo conhecimento a conhecimentos adquiridos e armazenados na memória anteriormente. Mas o desafio eminente dá-se em realizar atividades que envolvam três elementos: interdisciplinaridade, aprendizagem significativa e novas tecnologias. 
VIII Congresso Brasileiro de Informática na Educação (CBIE 2019)

Anais do XXV Workshop de Informática na Escola (WIE 2019)

Este desafio pode ser superado mediante a utilização das Tecnologias de Informação e Comunicação (TIC's), mais especificamente o uso do computador e da Internet. Ferramentas baseadas no computador, segundo [Machado 2007], são capazes de motivar os alunos na aquisição de novos conhecimentos, inclusive interdisciplinares. Desta maneira, nossa premissa é que a aprendizagem significativa pode ser estimulada por meio de uma WebQuest (WQ), possibilitando, além de motivação, diversas condições didático-pedagógicas para potencializar o ensino-aprendizado.

A metodologia WQ proporciona, ao professor, uma maneira inovadora de auxiliar a aprendizagem do aluno. A pesquisa online de forma orientada é uma forma eficaz de conduzir o aluno por uma trilha de aprendizado significativo. O pesquisador busca $\mathrm{o}$ objeto da pesquisa impulsionado pela curiosidade e pelo desejo da descoberta do novo. Assim, o aluno "navega" pela Internet, direcionado pela busca de informações que se associam a conhecimentos prévios aprendidos e, organiza-os na memória, montando seu mapa conceitual [Messa 2010].

Os resultados encontrados na busca podem ser apresentados de várias formas: material impresso, apresentação oral, slides, entre outros, inclusive publicando esse material na web. E foi pensando nesta última possibilidade, associando ao perfil do aluno atual que surgiu a proposta da WebFind (WF) [Oliveira 2014]. A WF trata-se da construção de uma página web com os achados de alguma WQ. A WF deve referenciar a WQ na qual está realizando a tarefa. Os links dos sites pesquisados devem ser disponibilizados na WF, devendo conter sites que são sugeridos na WQ.

É mediante a este potencial da pesquisa orientada, que acreditamos na metodologia WQ como uma forma mais abrangente e eficaz de possibilitar a relação entre aprendizagem significativa, interdisciplinaridade e tecnologia. A partir desse cenário, o artigo descreve uma proposta de WQ interdisciplinar com intuito de envolver disciplinas afins na promoção da aprendizagem significativa em alunos do $3^{\circ}$ ano do ensino médio de uma escola atendida pelo projeto 'Ação das TecnoLogias na Aprendizagem Significativa' (ATLAS) .

\section{Metodologia}

Com base no estudo bibliográfico foi desenvolvido o modelo de tarefa com as etapas de desenvolvimento do nosso trabalho, que foram as seguintes: i) analisamos o edital 2018 do ENEM; ii) selecionamos as disciplinas para compor a tarefa da WQ de maneira interdisciplinar; iii) elaboramos uma tarefa sobre sustentabilidade envolvendo a aprendizagem significativa e disciplinas afins; iv) desenvolvemos a WQ; e por fim, v) analisamos a utilização da mesma em uma atividade desenvolvida em sala de aula, através também da produção de um site pelos alunos.

\section{Tarefa proposta}

Com a crescente preocupação da preservação do meio ambiente, especialmente sua disponibilidade para gerações futuras. Questões como acesso e serviços de abastecimento de água e luz fazem parte das necessidades básicas da população. Ao mesmo tempo avolumam-se as evidências dos impactos decorrentes do contínuo uso desses recursos sem uma gestão adequada que busque garantir aspectos de sustentabilidade. É preciso que todos busquem entender a magnitude do problema. Assim, trabalhamos o tema Sustentabili- 
VIII Congresso Brasileiro de Informática na Educação (CBIE 2019)

Anais do XXV Workshop de Informática na Escola (WIE 2019)

dade na nossa WQ e dentro deste tema envolvemos algumas disciplinas, a saber: química, biologia, física e matemática. Disciplinas que o ENEM reconhece como: Matemática e suas tecnologias (matemática), Ciência da natureza e suas tecnologias (química, biologia e física).

A tarefa proposta na WQ consistiu na produção em equipe sobre consciência ambiental, produzindo uma página web, em formato HTML, a partir das informações encontradas em pesquisa a ser realizada na Internet e dos conhecimentos adquiridos em outras aulas. Para realização da tarefa , os alunos utilizaram a Internet como ferramenta de apoio durante a pesquisa, além de poder relatar observações do seu cotidiano, trazendo observações e vivências de sua realidade para a aprendizagem.

Inicialmente o aluno deverá pesquisar sobre o assunto Sustentabilidade, familiarizando-se com o tema neste primeiro momento. Após esse contato prévio com o tema, espera-se que o aluno desenvolva uma série de relações entre o assunto e seus conhecimentos nas disciplinas envolvidas na WQ. É solicitado, ainda, que a equipe pesquise sobre as causas e consequências do aquecimento global.

O trabalho deve conter desde informações sobre as variações climáticas até as composições dos gases poluentes, entre outras informações que certamente serão pensadas pelos alunos no decorrer da realização da tarefa, quando eles associarem o tema com seus conhecimentos adquiridos nas disciplinas.

Serão exigidos também, para a realização da tarefa, conhecimentos em informática, pois os alunos irão produzir gráficos com informações sobre a utilização dos materiais recicláveis em sua casa, para digitação do trabalho, entre outros. Por fim, as habilidades dos alunos para produção da WF.

\section{Webquest desenvolvida}

A nossa WQ está composta por seis páginas principais: início, introdução, tarefa, processo, avaliação e conclusão; e por cinco páginas com informações adicionais sobre: WQ, sustentabilidade, aprendizagem significativa, interdisciplinaridade e créditos (Ver a Figura 1). Dispõem ainda de imagens, vídeos e links que permeiam o tema e a realização da tarefa proposta. Assim, por meio da WQ, o aluno poderá então, seguir sua pesquisa sem a ajuda direta do professor, em uma experiência de ensino a distância.

Na introdução da WQ é abordada sobre o assunto Sustentabilidade e a descrição da referida WQ. Estimulando a importância em definir bem o que o aluno deverá fazer para que o mesmo não se perca na busca de informações disponíveis na Internet. Logo após a tarefa da WQ foi detalhada em tópicos a seguir: i) sobre o assunto sustentabilidade: pesquisar sobre o assunto na Internet, principalmente nas páginas que serão sugeridas na WQ; ii) gases poluentes: pesquisar sobre quais gases tem afetado a camada de ozônio e poluído o nosso ar, como também a composição química dos mesmos; iii) mudanças climáticas: buscar dados sobre a temperatura e as consequências das mudanças climáticas e os fenômenos meteorológicos; iv) qualidade de vida: pesquisar sobre os malefícios de toda a carga poluente nos seres vivos e logo após, pesquisar sobre o que deve ser feito para melhorar a qualidade de vida, com ações sustentáveis; v) exemplificação: inserir vídeos, imagens explicativas ou ainda um texto explicando o processo de reciclagem de algum material; e, vi) apresentação: produzir uma página web e publicar no site xpg.uol.com com os resultados da pesquisa. 
VIII Congresso Brasileiro de Informática na Educação (CBIE 2019)

Anais do XXV Workshop de Informática na Escola (WIE 2019)

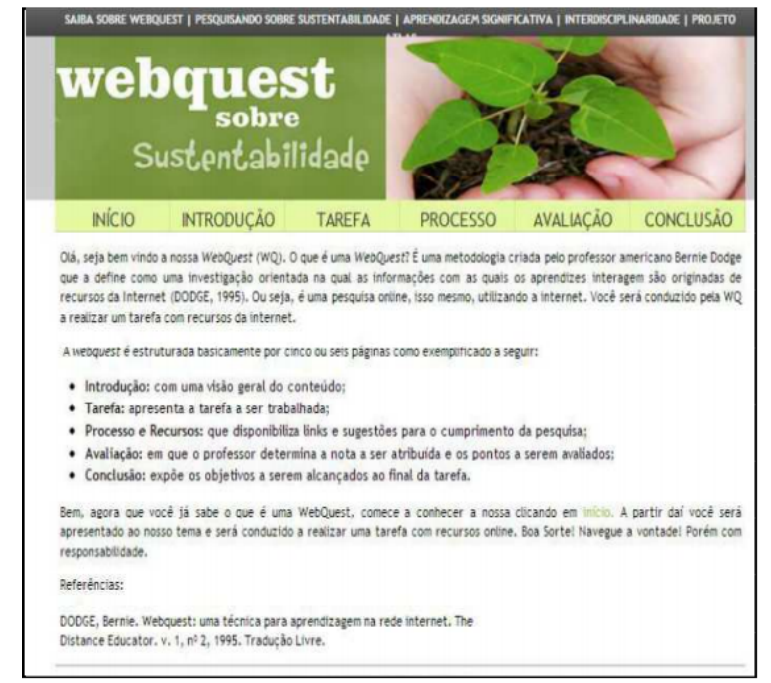

Figura 1. Página inicial da nossa WebQuest

Na página separada para o processo, orientamos as equipes a pesquisarem em sites seguros e confiáveis. Nesta página da WQ alertamos as equipes para a importância de referenciar a pesquisa e disponibilizar os links de imagens e sites que possam ter sido usados em seus trabalhos, evitando a prática do plágio. Ainda, nesta página, disponibilizamos links, na qual os alunos poderão encontrar sites confiáveis falando sobre o assunto da WQ.

Como avaliação, sugerimos que o professor avalie a construção de uma WF e se os alunos realizaram tudo o que foi solicitado na WQ, observando se as especificações da tarefa foram alcançadas, sendo que o aluno poderá ganhar um ponto extra com a demonstração da reciclagem, embora a nota não deva exceder a nota máxima: 10,0 (dez); deve-se observar se os alunos atentaram para sugestões do processo da WQ. Finalizando com a conclusão, desenvolvemos uma reflexão sobre o tema e o que ficará como aprendizado após a realização na tarefa da WQ.

\section{Estudo de caso}

Este estudo de caso aconteceu na Escola Dionísio da Costa durante cinco dias e prosseguiu na Universidade Estadual da Paraíba (UEPB) por mais cinco dias.

Nas cinco primeiras aulas foi explorada a linguagem HTML, com intuito de que conhecessem e trabalhassem com criação de páginas web. Ao final de cada aula era proposta uma atividade sobre o assunto da aula para ser desenvolvida em casa pelos alunos. Na última aula, ocorrida no laboratório de informática da escola, foi apresentada aos alunos, a metodologia WQ. Da mesma forma, apresentamos a metodologia WF - forma como os resultados seriam apresentados da pesquisa conduzida na WQ, ou seja, em forma de site, utilizando para tanto, os conhecimentos aprendidos nas aulas anteriores de HTML.

Após esse período, devido ao calendário escolar, as aulas passaram a acontecer na UEPB, quando os alunos foram divididos em quatro grupos e receberam orientações para produzir suas WF. Das quatro equipes formadas, três delas realizaram a atividade. $\mathrm{O}$ quarto grupo que não produziu a WF porque computaram muitas falhas. A Figura 2 apresenta o print screen da página inicial da WF desenvolvida por uma das três equipes. 
VIII Congresso Brasileiro de Informática na Educação (CBIE 2019)

Anais do XXV Workshop de Informática na Escola (WIE 2019)

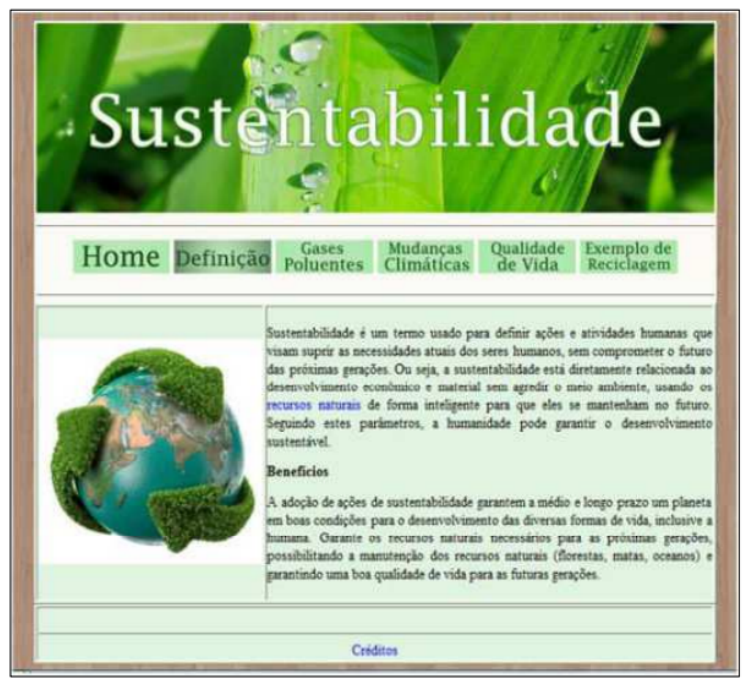

Figura 2. Página inicial de uma WF desenvolvida pelos alunos

Esta equipe citou a WQ para qual a WF foi dedicada e inseriu uma imagem 'linkando' a WQ. Essa WF foi estruturada em várias páginas, cada qual contemplando o que era solicitado na WQ. Todas as equipes referenciaram as imagens e sites pesquisados, inclusive utilizaram e citaram sites que foram sugeridos na WQ.

\section{Considerações finais}

A metodologia WQ demonstrou ser um instrumento eficaz para trabalhar com as gerações digitais, por ser uma ferramenta da cibercultura e utilizar o ciberespaço para promover uma atividade significativa para os nativos que já utilizam as TICs em seu cotidiano para as mais diversas tarefas. Associada a WQ, a WF é uma forma de divulgar e discutir a metodologia WQ. Bem como, é uma ferramenta da cibercultura e utiliza os saberes dos nativos digitais, fazendo com que eles sintam prazer em estar realizando uma pesquisa e produzindo um material em um 'espaço' tão familiar e explorado por eles, como é a Internet. A utilização da metodologia WQ e da produção da WF realizada com um grupo de alunos da escola participante demonstrou resultados satisfatórios, percebido a facilidade dos alunos em realizarem as atividades propostas.

\section{Referências}

Machado, R. C. (2007). Um software educativo de Exercício-e-prática como ferramenta no processo de alfabetização infanti. PhD thesis, Dissertação de Mestrado - Departamento de Engenharia Elétrica. Universidade Federal de Uberlândia, Uberlândia.

Messa, W. C. (2010). Utilização de ambientes virtuais de aprendizagem-avas: a busca por uma aprendizagem significativa. Revista brasileira de aprendizagem aberta e a distância, 9(1):1-49.

Oliveira, P. R. F. (2014). A webfind como resposta à webquest: Trabalhando como nativo digital na cibercultura, trabalho de conclusão de curso - licenciatura em computação. universidade estadual da paraíba, patos. 